\title{
A new multilevel inverter topology based on switched-capacitor technique
}

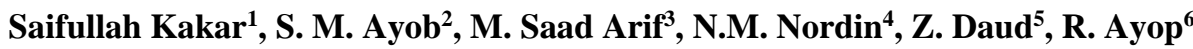 \\ 1,2,4,5,6 School of Electrical Engineering, Faculty of Engineering, Universiti Teknologi Malaysia, Johor Bahru, Malaysia \\ ${ }^{3}$ Department of Electrical Engineering, Aligarh Muslim University, Aligarh, India
}

\section{Article Info \\ Article history: \\ Received Oct 13, 2020 \\ Revised Feb 13, 2021 \\ Accepted Feb 20, 2021 \\ Keywords: \\ Fundamental switching frequency \\ Multilevel inverters \\ Switched capacitor \\ Self-balancing \\ Total blocking voltage}

\begin{abstract}
This paper presents a new multilevel inverter based on the switchedcapacitor technique. The topology aims for renewable energy and fuel cell applications that demand high magnitude output ac voltage. This configuration of the inverter can produce a total of thirteen voltage levels using a single DC source. The topology features voltage boosting with a triple gain of the input voltage source without utilizing a boost DC-DC converter. Furthermore, the voltages of the capacitors are self-balanced at any desired voltage level during each cycle. Therefore, auxiliary circuits are no longer needed. A comparative study of the presented inverter with the classical topologies and recently introduced topologies has been done in power switches, driver circuits, blocking voltage of the switches, and boosting the input voltage. A simple fundamental switching scheme is applied to the proposed topology to validate the viability of the topology.
\end{abstract}

This is an open access article under the CC BY-SA license.

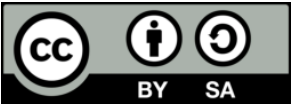

\section{Corresponding Author:}

Shahrin Md. Ayob

School of Electrical Engineering

Faculty of Engineering, Universiti Teknologi Malaysia

81310 UTM Skudai, Johor Darul Takzim, Malaysia

Email: shahrin@fke.utm.my

\section{INTRODUCTION}

Multilevel inverters (MLIs) have become very popular and globally recognized for numerous industrial applications such as renewable energy systems, motor drives, Induction heating, electric vehicles, FACTs devices, active power filtering, and many more. MLIs possess numerous advantages compared to classical two-level inverters, such as decreased total harmonic distortion (THD), lower voltage stress across switches, and electromagnetic interference (EMI). The basic principle of MLIs is to generate a staircase voltage waveform near to sinusoidal with high power quality. The desired staircase voltage waveform is synthesized using an appropriate combination of different switches, reducing power switches' voltage stress and total harmonic distortion (THD) [1]-[4].

Generally, well-established classical MLIs are categorized into the following three main types: Cascaded H-Bridge (CHB), Neutral-Point Clamped (NPC), and Flying-Capacitor (FC). NPC MLIs are widely used in the industry. However, high-level NPC inverter structures require several clamping diodes and capacitors' balancing involving auxiliary circuits and sensors, making the system more complicated, less reliable, and more costly to maintain. The FC MLI is another inverter topology with an energy storage facility. The flying capacitors' voltage can be maintained at their respective levels using the topology's switching state redundancies. Thus, the voltage balancing mechanism becomes complicated. It is the prerequisite of too many bulky flying capacitors, and the complex control mechanism for capacitors balancing that limits higher levels on this inverter. The CHB MLIs, on the other hand, consists of several $\mathrm{H}$ - 
bridge cells to produce multilevel output. However, these CHB MLIs are constructed using multiple isolated power sources, which somehow not suitable in many applications such as electric vehicle drives. Moreover, they generally employ more power switches, gate drives and resulting in more power losses. These issues motivate researchers to develop new inverter topologies, and to date, many inverter structures addressing those issues have been introduced in the literature[5]-[15].

Recent MLI topologies [5]-[15] tend to focus on increasing the efficiency and modularity of the MLIs. Hence, most of them have a more straightforward structure [3], but they are buck-type MLIs. They are not able to boost up the output voltage. Typically, a front-end DC-DC boost converter is required, which leading to complex control and structures. The boosting of input voltage should be the essential feature for the inverter topologies used for high voltage and renewable energy systems (RES). One such type of MLIs topologies is the switched capacitor (SC) based MLIs. In general, SC-MLIs contain a single DC source connected in various capacitors' configurations to boost the low input voltage.

Moreover, without any auxiliary circuits, the capacitor's voltage is self-balanced in SC-MLIs [16]. The boosting voltage ability and non-auxiliary circuits for balancing the capacitor voltage are remarkable benefits provided by these SC-MLIs. However, the existing SC-MLIs topologies consisted of many power switches and capacitors with high voltage stress; thus, the overall system becomes problematic, costly with high power losses. Hence, research on developing new SC-based MLIs to use fewer switches and capacitors with low voltage stress progresses [16]-[38].

SC-MLIs presented in [16]-[20] use a back-end H-bridge circuit for polarity change. This inverter exhibits a simple structure with a high number of voltage levels. However, four power switches in those structures must withstand high voltage stress equal to the load's peak voltage. It put limitations on these topologies for higher voltage applications. Other SC-MLI were proposed in the literature [39-41]. They require two switches only to withstand the blocking voltage equal to the peak output voltage. However, the voltage blocking rating is still regarded as high.

In this paper, a new SC-MLI topology is proposed. The advantages of the proposed SC-MLI topology include; 1 . self-voltage balancing of capacitors without using auxiliary circuits and sensors; 2 . Input voltage can boost with a gain of three; 3 . a single DC source to generate multiple output voltage levels and 4. low voltage rated power switches. The total standing voltage (TSV) of the SC-MLI will be shown to be at the low side even though fewer components are employed. The design of the proposed SC-MLI will be elaborated on in the following sections. A simple fundamental switching scheme is used for the proposed SCMLI to generate the 13-level output voltage. Simulation using Matlab-Simulink® software will be performed using different loading. From the results, it will be shown that the design of the proposed SC-MLI is validated.

\section{THE PROPOSED MULTILEVEL INVERTER}

The configuration of the proposed inverter topology is depicted in Figure 1. The topology consists of 11 unidirectional switches, a bidirectional switch $\left(\mathrm{S}_{11}\right)$, a diode, and three switched capacitors. With this inverter configuration, thirteen voltage levels can be achieved. The voltage of switched capacitor $\mathrm{C}_{1}$ is balanced at a voltage level equal to Vin input voltage. Simultaneously, the input DC source of magnitude $\mathrm{V}_{\text {in }}$ charges switched capacitors $\mathrm{C}_{2}$ and $\mathrm{C}_{3}$ to the voltage level of $0.5 \mathrm{Vin}$. As the capacitor's voltages are selfbalancing in nature, sensors and auxiliary circuits are not required to balance switched capacitors in the presented inverter topology. Figure 2 depicts the pulses to generate a 13-level output voltage.

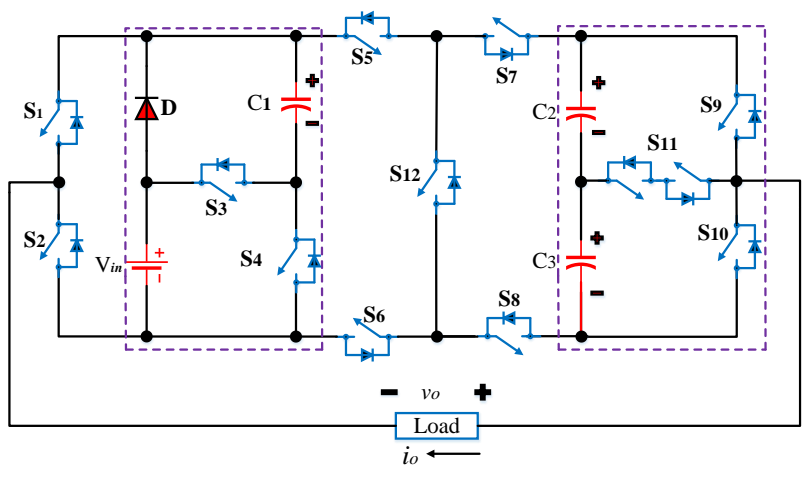

Figure 1. Proposed boost MLI circuit 


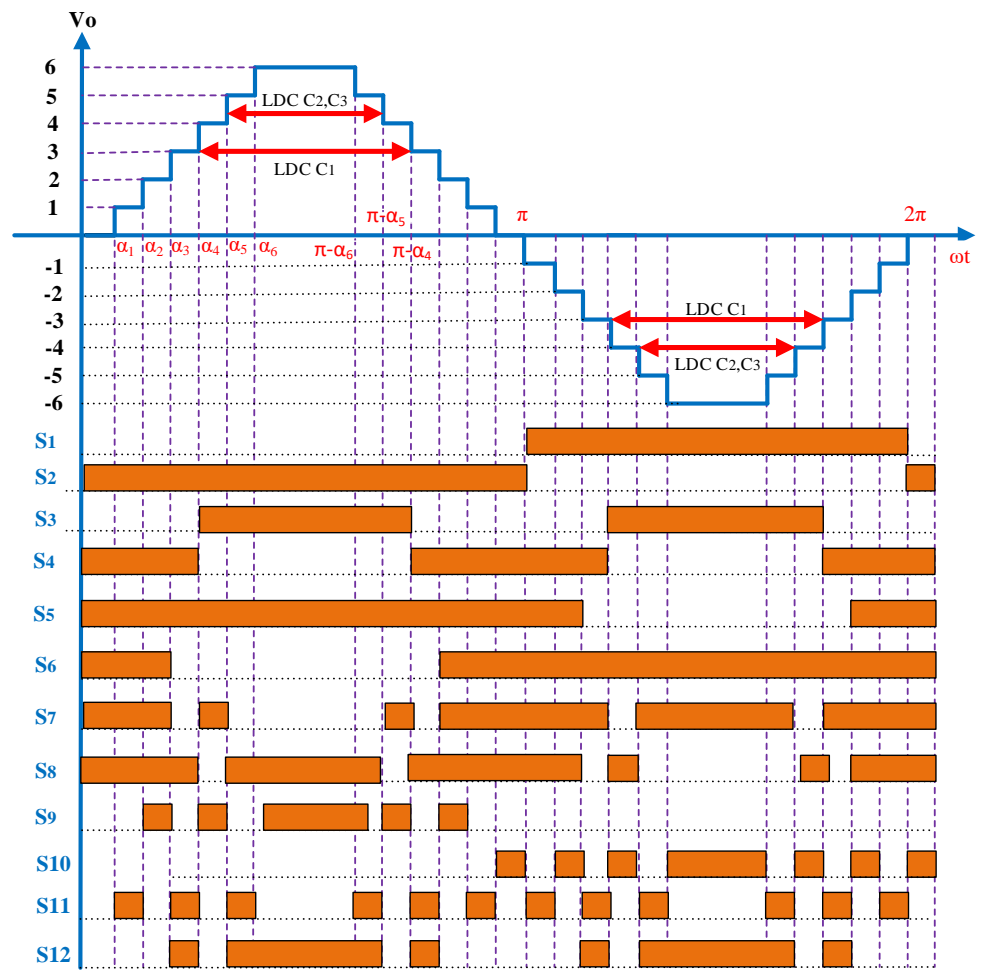

Figure 2. 13-level output voltage waveform and required pulses for switches

\subsection{Modes of Operation}

In this Section 2.1, the modes of operations that provide the basic principle of generating different voltage levels across the load are presented. The proposed SC-MLI operation modes in positive and negative half-cycles are shown in Figures 3 and 4, respectively. Table 1 shows all the switching states of the proposed SC-MLI. Here ' 1 ' and ' 0 ' represent on and off states of the switches, respectively. The charging state, discharging, and no-effect state of the switched capacitors are represented by ' $\mathrm{C}$ ', 'D', and ' $\mathrm{N}$ ', respectively. The upward arrow sign ' $\uparrow$ ' shows the charging of switched capacitors while the downward sign ' $\downarrow$ ' shows the discharging of switched capacitors. The blue dotted line shows the path for charging of switched capacitors, while the red dotted lines show the direction of load current. The following paragraphs explain the mode of operation of the proposed SC-MLI in generating different output levels.

$\pm 0.5 V_{\text {in }}$ Voltage level: As shown in Figure 3(a), the switches $S_{2}, S_{6}, S_{8}$, and $S_{11}$ are turned on to produce voltage level $0.5 \mathrm{~V}_{\mathrm{in}}$. Switch $\mathrm{S}_{4}$ is turned on; thus, the diode is in forwarding conduction mode. The switched capacitor $C_{1}$ is parallel with the input DC source and charges it to $V_{\text {in }}$ magnitude. The switched capacitors $C_{2}$ and $C_{3}$ are also parallel with input DC when switches $S_{5}$ and $S_{7}$ are turned on. It charges these capacitors to the voltage level of $0.5 \mathrm{~V}_{\text {in }}$. To produce a voltage level of $-0.5 \mathrm{~V}_{\text {in }}$, the switches $\mathrm{S}_{1}, \mathrm{~S}_{5}, \mathrm{~S}_{7}$, and $\mathrm{S}_{11}$ are turned on, as shown in Figure 4(a). The process of charging the switched capacitors will remain the same as in the $0.5 \mathrm{~V}_{\text {in }}$ state.

$\pm 1 V_{\text {in }}$ Voltage level: As shown in Figure $3(\mathrm{~b})$, the switches $S_{2}, S_{6}, S_{8}$, and $S_{9}$ are turned on to produce voltage level $1 V_{\text {in. }}$. The switched capacitor $C_{1}$ is parallel with the input DC source through $S_{4}$ and the diode. The capacitor charges to $V_{\text {in }}$ magnitude. The switched capacitors $C_{2}$ and $C_{3}$ are also in parallel combination with input DC when switches $\mathrm{S}_{6}$ and $\mathrm{S}_{8}$ are turned on. It charges these capacitors to the voltage level of $0.5 \mathrm{~V}_{\text {in }}$. To produce voltage level $-1 \mathrm{~V}_{\text {in }}$, the switches $\mathrm{S}_{1}, \mathrm{~S}_{6}, \mathrm{~S}_{8}$, and $\mathrm{S}_{10}$ are turned on, as shown in Figure $4(\mathrm{~b})$. The process of charging the switched capacitors will remain the same as in the $1 \mathrm{~V}_{\text {in }}$ state.

$\pm 1.5 \mathrm{~V}_{\text {in }}$ Voltage level: As shown in Figure 3(c), the switches $\mathrm{S}_{2}, \mathrm{~S}_{5}, \mathrm{~S}_{8}, \mathrm{~S}_{11}$, and $\mathrm{S}_{12}$ are turned on to produce voltage level $1.5 \mathrm{~V}_{\text {in. }}$. The switched capacitors $\mathrm{C}_{3}$ is in series combination with input source and discharges. At that moment, there is no effect on capacitor $\mathrm{C}_{2}$ in this state. Switch $\mathrm{S}_{4}$ is turned on; thus, the diode is in forward conduction mode. The switched capacitor $C_{1}$ is parallel with the input DC source and charges it to the magnitude of $1 \mathrm{~V}_{\text {in }}$. To produce voltage level $-1.5 \mathrm{~V}_{\text {in, }}$, the switches $\mathrm{S}_{1}, \mathrm{~S}_{6}, \mathrm{~S}_{7} \mathrm{~S}_{11}$, and $\mathrm{S}_{12}$ are turned on as shown in Figure 4(c). The process of charging the switched capacitors will remain the same as in the $0.5 \mathrm{~V}_{\text {in }}$ state. In this state, $\mathrm{C}_{3}$ provides the power to load in series combination with input source and discharges, while $\mathrm{C}_{2}$ remains not affected. 
Table 1. Switching states of the 13-level inverter

\begin{tabular}{|c|c|c|c|c|c|c|c|c|c|c|c|c|c|c|c|c|}
\hline \multirow[t]{2}{*}{ levels } & \multirow[b]{2}{*}{$\mathbf{S}_{1}$} & \multirow[b]{2}{*}{$\mathbf{S}_{2}$} & \multicolumn{8}{|c|}{ Power switches } & \multicolumn{6}{|c|}{ Capacitors } \\
\hline & & & $\mathbf{S}_{\mathbf{3}}$ & $\mathbf{S}_{4}$ & $\mathbf{S}_{5}$ & $S_{6}$ & $\mathbf{S}_{7}$ & $\mathbf{S}_{8}$ & $\mathbf{S}_{9}$ & $\mathbf{S}_{10}$ & $\mathbf{S}_{11}$ & $\mathbf{S}_{12}$ & $\mathbf{C}_{1}$ & $\mathbf{C}_{2}$ & $\mathbf{C}_{3}$ & $\mathbf{V}_{\mathbf{o}}$ \\
\hline 1 & 0 & 1 & 0 & 1 & 1 & 1 & 1 & 1 & 0 & 0 & 1 & 0 & $\mathrm{C}$ & $\mathrm{C}$ & $\mathrm{C}$ & $0.5 V_{\text {in }}$ \\
\hline 2 & 0 & 1 & 0 & 1 & 1 & 1 & 1 & 1 & 1 & 0 & 0 & 0 & $\mathrm{C}$ & $\mathrm{C}$ & $\mathrm{C}$ & $1 V_{\text {in }}$ \\
\hline 3 & 0 & 1 & 0 & 1 & 1 & 0 & 0 & 1 & 0 & 0 & 1 & 1 & $\mathrm{C}$ & $\mathrm{N}$ & $\mathrm{D}$ & $1.5 \mathrm{~V}_{\text {in }}$ \\
\hline 4 & 0 & 1 & 1 & 0 & 1 & 0 & 1 & 0 & 1 & 0 & 0 & 0 & $\mathrm{D}$ & $\mathrm{N}$ & $\mathrm{N}$ & $2 V_{\text {in }}$ \\
\hline 5 & 0 & 1 & 1 & 0 & 1 & 0 & 0 & 1 & 0 & 0 & 1 & 1 & D & $\mathrm{N}$ & D & $2.5 \mathrm{~V}_{\text {in }}$ \\
\hline 6 & 0 & 1 & 1 & 0 & 1 & 0 & 0 & 1 & 1 & 0 & 0 & 1 & D & D & D & $3 V_{D C}$ \\
\hline 0 & 0 & 1 & 0 & 1 & 1 & 1 & 1 & 1 & 0 & 1 & 0 & 0 & $\mathrm{C}$ & $\mathrm{C}$ & $\mathrm{C}$ & 0 \\
\hline-1 & 1 & 0 & 0 & 1 & 1 & 1 & 1 & 1 & 0 & 0 & 1 & 0 & $\mathrm{C}$ & $\mathrm{C}$ & $\mathrm{C}$ & $-0.5 V_{\text {in }}$ \\
\hline-2 & 1 & 0 & 0 & 1 & 1 & 1 & 1 & 1 & 0 & 1 & 0 & 0 & $\mathrm{C}$ & $\mathrm{C}$ & $\mathrm{C}$ & $-1 V_{\text {in }}$ \\
\hline-3 & 1 & 0 & 0 & 1 & 0 & 1 & 1 & 0 & 0 & 0 & 1 & 1 & $\mathrm{C}$ & D & $\mathrm{N}$ & $-1.5 V_{\text {in }}$ \\
\hline-4 & 1 & 0 & 1 & 0 & 0 & 1 & 0 & 1 & 0 & 1 & 0 & 0 & $\mathrm{D}$ & $\mathrm{N}$ & $\mathrm{N}$ & $-2 V_{\text {in }}$ \\
\hline-5 & 1 & 0 & 1 & 0 & 0 & 1 & 1 & 0 & 0 & 0 & 1 & 1 & D & D & $\mathrm{N}$ & $-2.5 V_{\text {in }}$ \\
\hline-6 & 1 & 0 & 1 & 0 & 0 & 1 & 1 & 0 & 0 & 1 & 0 & 1 & D & D & D & $-3 V_{\text {in }}$ \\
\hline
\end{tabular}

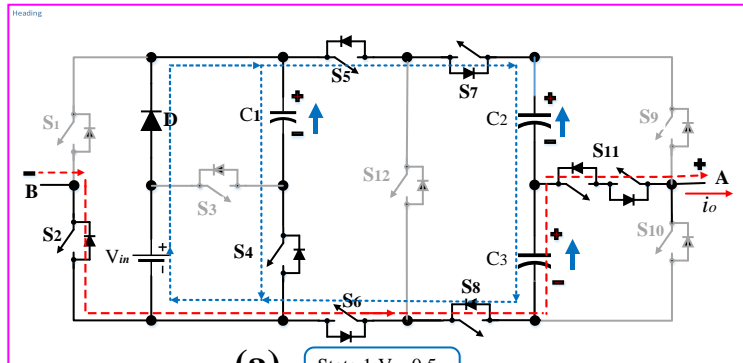

(a) State $1: \mathrm{V}_{0}=0.5 \mathrm{v}$

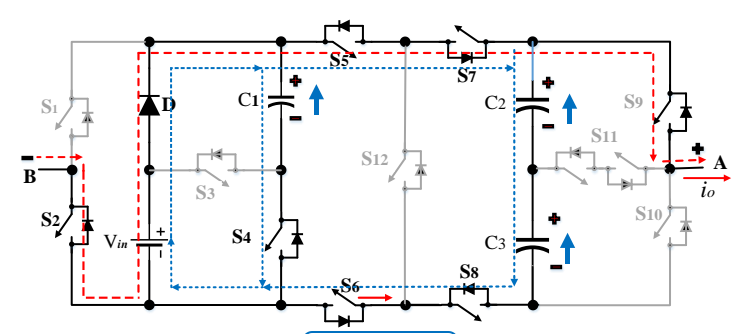

(b)

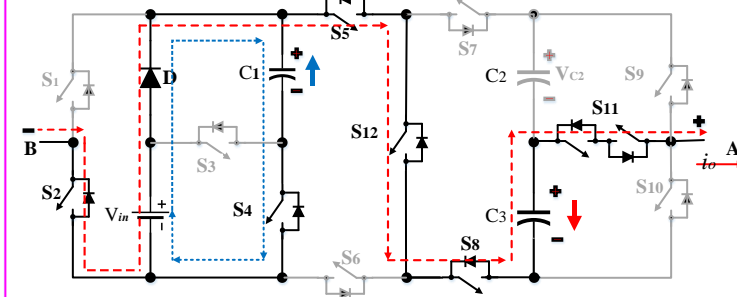

(c) State $3: \mathrm{V}_{\mathrm{o}}=1.5 \mathrm{v}$

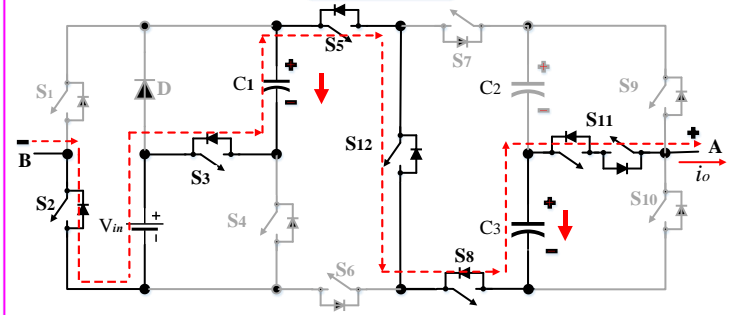

(e) State $5: \mathrm{V}_{0}=2.5 \mathrm{v}$

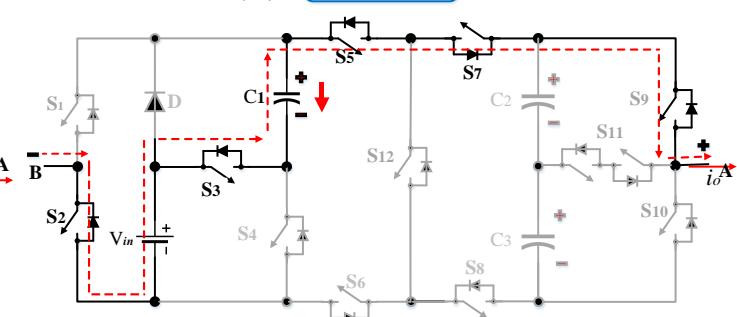

(d) $\quad$ State $4: V_{0}=2 v$

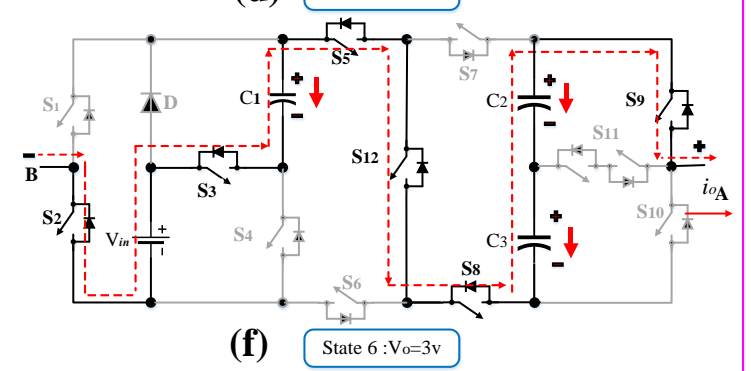

Figure 3. Operating modes of inverter during the positive half cycle

$\pm 2 V_{\text {in }}$ Voltage level: As shown in Figure 3(d), the switches $S_{2}, S_{3}, S_{5}, S_{7}$, and $S_{9}$ are turned on to produce voltage level $+2 V_{\text {in }}$. The switched capacitors $C_{1}$ is in series combination with the input source to provide the load current and discharges. Simultaneously, there is no effect on capacitors $\mathrm{C}_{2}$ and $\mathrm{C}_{3}$ in this mode of operation. To produce voltage level $-2 V_{\text {in }}$, the switches $S_{1}, S_{3}, S_{6} S_{8}$, and $S_{10}$ are turned on as shown in Figure $4(d)$. The switched capacitors $C_{1}$ discharge as they come in series with the input source. At the same time, there is no effect on capacitors $\mathrm{C}_{2}$ and $\mathrm{C}_{3}$ in this state.

$\pm 2.5 \mathrm{~V}_{\text {in }}$ Voltage level: As shown in Figure 3(e), to generate the voltage level $+2 \mathrm{~V}_{\text {in, }}$, the switches $\mathrm{S}_{2}$, $S_{3}, S_{5}, S_{8} S_{11}$ and $S_{12}$ are turned $O N$. The switched capacitors $C_{1}$ and $C_{3}$ are combined with the input source to provide the load current and discharges. At the same time, there is no effect on capacitors $\mathrm{C}_{3}$ in this mode of 
operation. While in voltage level $-2 V_{\text {in, }}$, the switched capacitors $C_{1}$ and $C_{2}$ discharge as they come in series with the input source. The capacitors $\mathrm{C}_{2}$ remains unaffected in this state.

$\pm 3 \mathrm{~V}_{\text {in }}$ Voltage level: As shown in Figure. 3(f), in this mode of operation to produce voltage level $\pm 3 \mathrm{~V}_{\text {in }}$, all the switched capacitors $\mathrm{C}_{1}, \mathrm{C}_{2}$ and $\mathrm{C}_{3}$ are combined with the input source to provide the load current and therefore discharges.

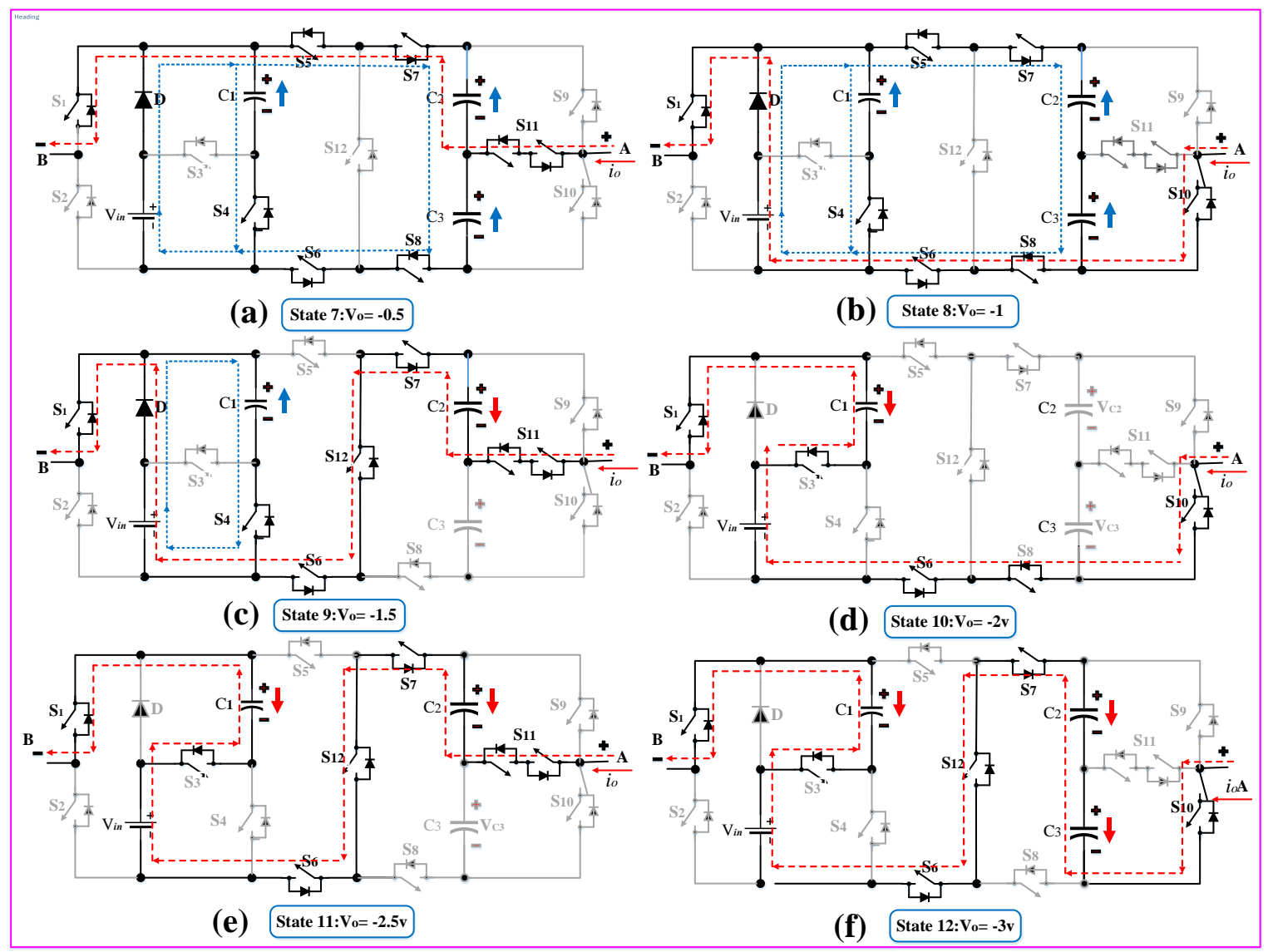

Figure 4. Operating modes of inverter during the negative half cycle

\subsection{Modulation technique and Capacitor Value Calculation}

In this paper, the fundamental switching frequency method is used to generate pulses for all the switches. A sinusoidal $50 \mathrm{~Hz}$ reference signal is compared with some available DC-voltage levels and generates related pulses for power switches. This switching technique's main advantage is low switching frequency, which significantly reduces the switching losses. Details of the fundamental switching frequency technique are not discussed here.

Generally, the switching angles $\theta_{i}$ can be obtained as (1)

$$
\theta_{i}=\sin ^{-1}\left(\frac{2 i-1}{N_{l}}\right), i=1,2,3, \ldots, \frac{N_{l}-1}{2}
$$

In switched capacitor MLIs, the capacitor's optimum calculation is one of the most critical issues to retain the capacitor's voltage ripples in an acceptable range. For calculating capacitors' capacitance, the longest discharging cycle (LDC) for each capacitor over a complete output voltage cycle is considered. The capacitor discharges the maximum amount of charge during LDC. The value of discharging charge is dependent on the output current and LDC duration.

Therefore, the maximum discharging amount of the capacitor's charge is obtained by (2) and (3)

$$
\Delta Q_{1}=\frac{1}{2 \pi f_{0}} \int_{\theta_{4}}^{\pi-\theta_{4}} I_{o} d \omega t
$$




$$
\Delta Q_{2,3}=\frac{1}{2 \pi f_{0}} \int_{\theta_{5}}^{\pi-\theta_{5}} I_{o} d \omega t
$$

Where, $f_{0}$ is the frequency of output waveform, $\mathrm{I}_{0}$ is the amplitude of load current, and $\omega$ is the corresponding angular frequency. Whereas, $\left[\theta_{4}, \pi-\theta_{4}\right]$ is the longest discharging cycle (LDC) of the capacitor $C_{1}$ and $\left[\theta_{5}, \pi-\theta_{5}\right]$ is the LDC interval of the capacitor $C_{2}$ and $C_{3}$. Thus, by assuming $\Delta \mathrm{V}$ as the maximum allowable voltage ripple over the capacitor, the optimum capacitance values of switched capacitors can be calculated by (4) and (5)

$$
\begin{aligned}
& C_{1}=\frac{\Delta Q_{1}}{\Delta V}=\frac{1}{\Delta V} \frac{1}{2 \pi f_{0}} \int_{\theta_{4}}^{\pi-\theta_{4}} I_{o} d \omega t \\
& C_{2,3}=\frac{\Delta Q_{2,3}}{\Delta V}=\frac{1}{\Delta V} \frac{1}{2 \pi f_{0}} \int_{\theta_{5}}^{\pi-\theta_{5}} I_{o} d \omega t
\end{aligned}
$$

\subsection{Comparatives study}

Table. 2 presents the comparison study with other recently introduced MLIs, considering the capability of voltage boosting and self-balancing of switched capacitors. For generating 13-level voltage, the proposed SC-MLI topology requires the least component counts in power switches and gate drives. Moreover, it is achieved using a single DC source. The other topologies require more switches to attain the same voltage levels. The voltage stress across the power switches in the proposed topology is much lower than the rest topologies. It is clear from the comparison that the proposed topology requires the least number of power switches and blocking voltage compared to other inverter structures. Please be noted that TSV is defined as Total Standing Voltage, which is similar to the total voltage value that needs to be blocked by the power switch during its off state.

Table 2. Comparative analysis with other recently introduced SCMLIs

\begin{tabular}{ccccccc}
\hline & {$[32]$} & {$[19]$} & {$[16]$} & {$[20]$} & {$[34]$} & Proposed \\
\hline Levels & 13 & 9 & 13 & 13 & 9 & 13 \\
switches & 29 & 10 & 16 & 14 & 14 & 13 \\
driver & 29 & 8 & 16 & 4 & 2 & 10 \\
capacitors & 5 & 2 & 4 & 2 & 1 & 3 \\
sources & 1 & 1 & 2 & 78 & 22 & 1 \\
$(\mathrm{TSV}) * \mathrm{~V}_{\text {in }}$ & 29 & 24 & 34 & & & 13.5 \\
\hline
\end{tabular}

\section{RESULTS AND DISCUSSION}

Simulations are carried out using the Matlab-Simulink@ computer software tool. A single-phase 13level inverter was developed for simulation purposes with different parameters used as tabulated in Table 3. In this work, the fundamental frequency switching method is employed to generate the required gating pulse for the power switches. The selected input voltage source is $100 \mathrm{~V}$ for simulation purposes, and the resistive load of $150 \Omega$ and the inductive load of $150 \Omega$ and $100 \mathrm{~m} \mathrm{H}$ are used for the proposed SC-MLI. Figures 5(a-b) illustrates the output voltage and current waveforms for the proposed SC-MLI. The output voltage and current have a peak of $297.5 \mathrm{~V}$ and 1.9 A, respectively. The voltage is boosted triple times from the $100 \mathrm{~V}$ input voltage value. It proves the viability of the proposed SC-MLI. The result with inductive load also confirms the capability of the proposed SC-MLI to operates with bi-directional capabilities.

Table 3. Parameters used for the simulation study

\begin{tabular}{cc}
\hline Parameters & value \\
\hline Input voltage & $100 \mathrm{~V}$ \\
Capacitances & $\mathrm{C}_{1}=1200 \mu \mathrm{F}$ \\
& $\mathrm{C}_{11,}, \mathrm{C}_{1,2}=1000 \mu \mathrm{F}$ \\
Modulation indices & $\mathrm{M}_{\mathrm{a}}=1$, \\
Output frequency & $\mathrm{M}_{\mathrm{a}}=0.7$ \\
Input frequency & $50 \mathrm{~Hz}$ \\
Load & $50 \mathrm{~Hz}$ \\
\hline
\end{tabular}

As depicted in Figure 5(c-d), the harmonic spectrum of the output voltage contains $4.65 \%$ THD without using filters, while the harmonic spectrum of sinusoidal output current is having $2.53 \%$ THD. All the obtained results satisfy the harmonics IEEE standards, i.e., IEEE519. The 13 levels at the output with 
triple voltage gain and inductive load ability are validated through simulations. The current stress of the power switches is shown in Figure6 (a). By considering a $10 \%$ voltage ripple, the optimum value of capacitor $\mathrm{C}_{1}$ obtained is approximately $1200 \mu \mathrm{F}$ and $1000 \mu \mathrm{F}$ for capacitors of $\mathrm{C}_{2}$ and $\mathrm{C}_{3}$.

The switched capacitors voltages at the rated output and current waveforms are shown in Figure 7. The capacitor voltage of $C_{1}$ is maintained at $100 \mathrm{~V}$, while $C_{2}$ and $C_{3}$ are maintained at $50 \mathrm{~V}$, respectively. The result verifies the self-balancing of all three switched capacitors. The voltage ripples of the capacitors can also be observed. The maximum voltage ripples of $\mathrm{C}_{1}$ are about $9 \mathrm{~V}$, while capacitors $\mathrm{C}_{2}$ and $\mathrm{C}_{3}$ are around 8 $\mathrm{V}$. The blocking voltage of each switch in the inverter is shown in Figure 6(b).

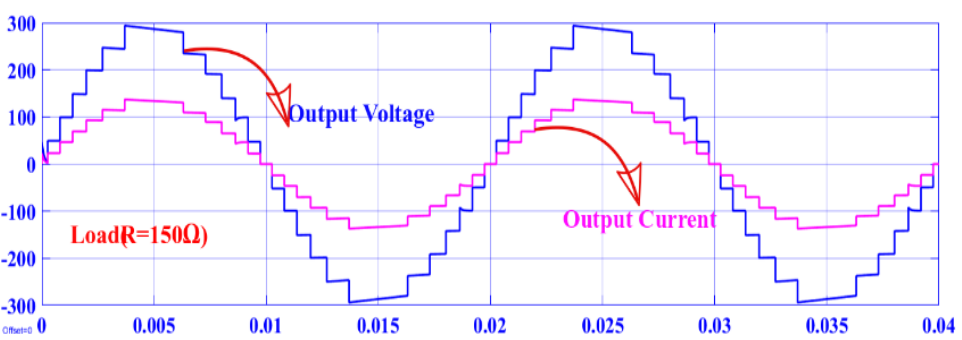

(a)

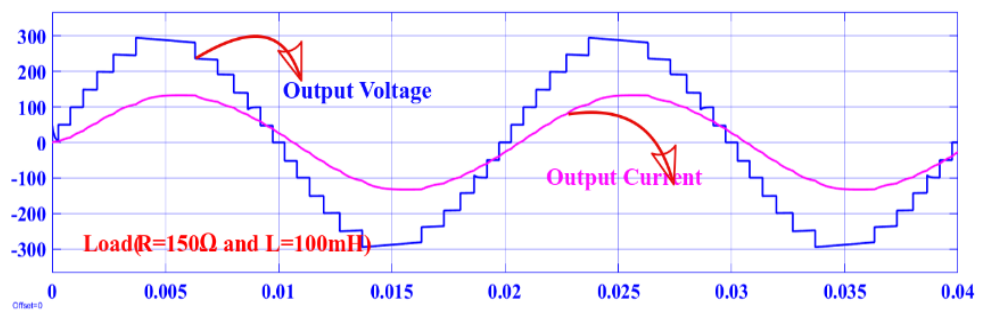

(c)

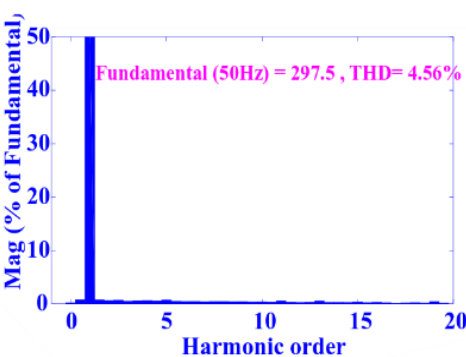

(b)

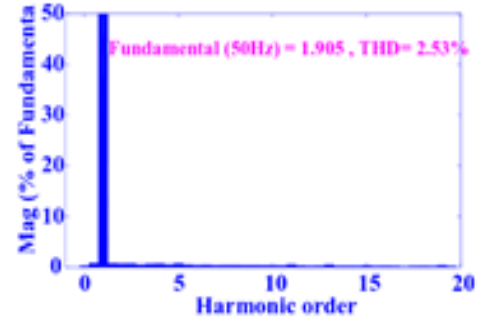

(d)

Figure 5. Output voltage and current waveforms, (a) resistive load, (b) inductive load, Harmonic spectrums, (c) output voltage, $(\mathrm{d})$ current

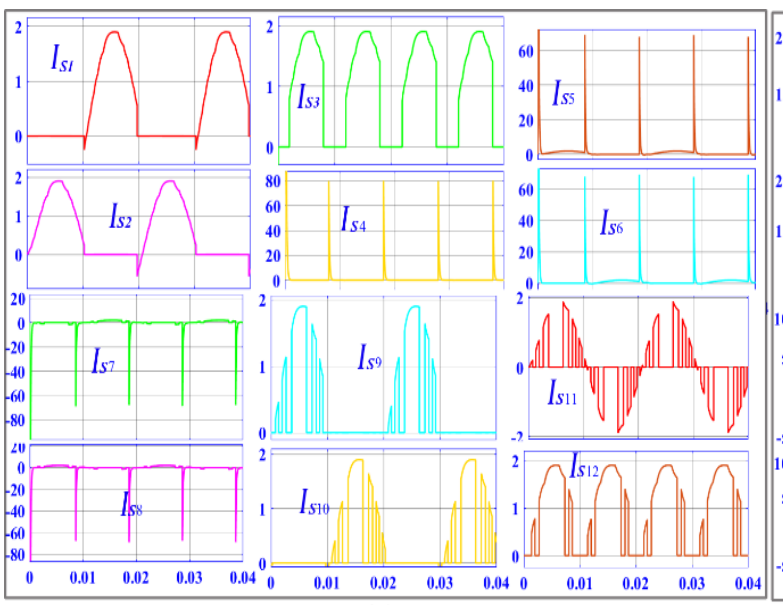

(a)

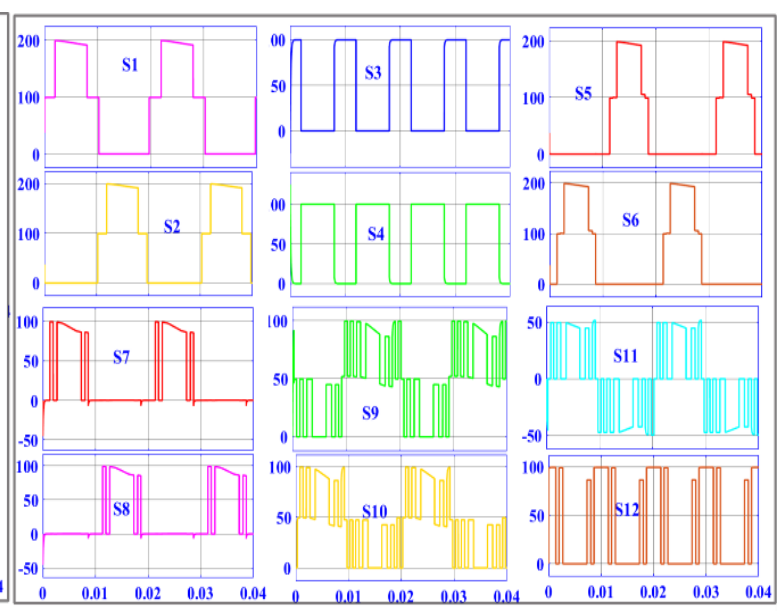

(b)

Figure 6. (a) Current through power switches, (b) Blocked voltages across power switches 


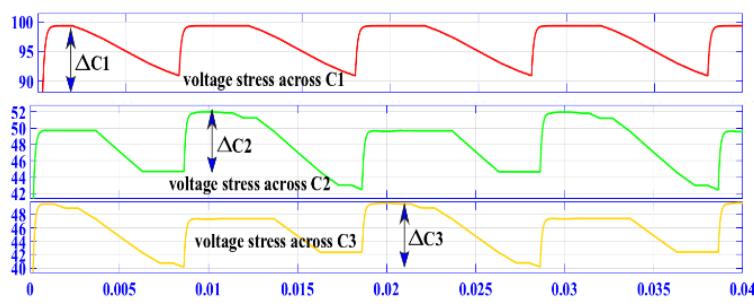

(a)

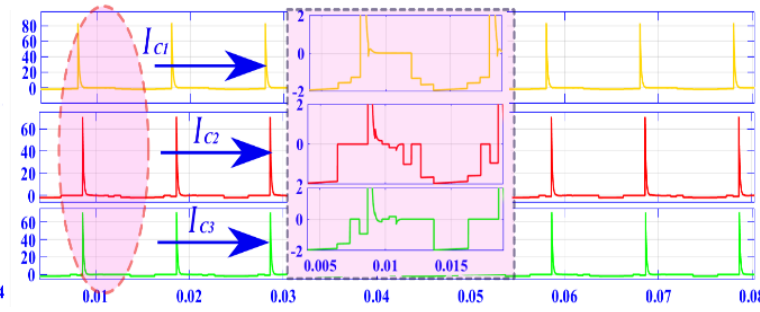

(b)

Figure 7. Voltage and current waveforms of the capacitors $\left(\mathrm{V}_{\mathrm{c} 1} \mathrm{~V}_{\mathrm{c} 2}\right.$, and $\left.\mathrm{V}_{\mathrm{c} 3}\right)$

\section{CONCLUSION}

This paper has proposed a new SC-MLI based on the switched-capacitor technique. The inverter has the capability of triple-voltage boosting and self-voltage balancing of switched capacitors. The working principle and different modes of operation with switched capacitors and their charging-discharging cycles have been addressed. This proposed SC-MLI generates a 13-level output voltage waveform by employing only a single input source. The voltage stress across the power switches is also proven to be on the low side. Simulations results with the 13-level inverter topology at different load conditions were obtained. Comparative study of the proposed SC-MLI with other inverter topologies shows the superiority of the proposed topology in reducing the number of power switches, the voltage stress on switches, size, and cost of the inverter system.

\section{ACKNOWLEDGEMENT}

The authors would like to thank the Ministry of High Education Malaysia (MOHE) and Universiti Teknologi Malaysia under UTMER research Grant, vot.no - 19J80, for sponsoring this research.

\section{REFERENCES}

[1] J. Rodriguez, J.-S. Lai, and F. Z. Peng, "Multilevel inverters: a survey of topologies, controls, and applications," IEEE Transactions on industrial electronics, vol. 49, no. 4, pp. 724-738, 2002.

[2] L. M. Tolbert, F. Z. Peng, and T. G. Habetler, "Multilevel converters for large electric drives," IEEE Transactions on Industry Applications, vol. 35, no. 1, pp. 36-44, 1999.

[3] K. K. Gupta, A. Ranjan, P. Bhatnagar, L. K. Sahu, and S. Jain, "Multilevel inverter topologies with reduced device count: A review," IEEE transactions on Power Electronics, vol. 31, no. 1, pp. 135-151, 2015.

[4] L. G. Franquelo, J. Rodriguez, J. I. Leon, S. Kouro, R. Portillo, and M. A. Prats, "The age of multilevel converters arrives," IEEE industrial electronics magazine, vol. 2, no. 2, pp. 28-39, 2008.

[5] N. Prabaharan, Z. Salam, C. Cecati, and K. Palanisamy, "Design and Implementation of New Multilevel Inverter Topology for Trinary Sequence Using Unipolar Pulsewidth Modulation,” IEEE Transactions on Industrial Electronics, vol. 67, no. 5, pp. 3573-3582, 2020.

[6] S. T. Meraj, N. Z. Yahaya, K. Hasan, and A. Masaoud, "Single phase 21 level hybrid multilevel inverter with reduced power components employing low frequency modulation technique," International Journal of Power Electronics and Drive Systems, vol. 11, no. 2, p. 810, 2020.

[7] E. Samadaei, A. Sheikholeslami, S. A. Gholamian, and J. Adabi, "A square T-type (ST-Type) module for asymmetrical multilevel inverters," IEEE Transactions on power Electronics, vol. 33, no. 2, pp. 987-996, 2017.

[8] S. Kakar, S. Ayob, N. Nordin, M. Arif, A. Jusoh, and N. Muhamad, "A novel single-phase PWM asymmetrical multilevel inverter with number of semiconductor switches reduction," International Journal of Power Electronics and Drive Systems (IJPEDS), vol. 10, no. 3, p. 1133, 2019.

[9] A. Chlaihawi, A. Sabbar, and H. Jedi, "A high-performance multilevel inverter with reduced power electronic devices," International Journal of Power Electronics and Drive Systems (IJPEDS), vol. 11, no. 4, pp. 1883-1889, 2020.

[10] S. Kumar and M. S. Kumar, "Asymmetric hybrid multilevel inverter with reduced harmonic using hybrid modulation technique," International Journal of Power Electronics and Drive Systems (IJPEDS), vol. 11, no. 2, p. $605,2020$.

[11] M. Jagabar Sathik, N. Prabaharan, S. A. Ibrahim, K. Vijaykumar, and F. Blaabjerg, "A new generalized switched diode multilevel inverter topology with reduced switch count and voltage on switches," International Journal of Circuit Theory and Applications, vol. 48, no. 4, pp. 619-637, 2020.

[12] H. Javvaji and B. Banakara, "An enhanced 17-level hybridized multilevel inverter with stair case modulation," International Journal of Power Electronics and Drive Systems (IJPEDS), vol. 2088, p. 8694, 2020. 
[13] S. S. Lee, M. Sidorov, N. R. N. Idris, and Y. E. Heng, "A symmetrical cascaded compact-module multilevel inverter (CCM-MLI) with pulsewidth modulation," IEEE Transactions on Industrial Electronics, vol. 65, no. 6, pp. 4631-4639, 2017.

[14] M. Setti and M. Cherkaoui, "Design and implementation of an optimized multilevel power inverter structure based on C MEX and PSPICE," International Journal of Power Electronics and Drive Systems (IJPEDS), vol. 11, no. 3, p. $1388,2020$.

[15] A. Razi, M. N. Hidayat, M. Seroji, and S. M. Noor, "A novel single-stage PWM microinverter topology using twopower switches," International Journal of Power Electronics and Drive Systems (IJPEDS), vol. 11, no. 2, p. 792, 2020.

[16] T. Roy, P. K. Sadhu, and A. Dasgupta, "Cross-Switched Multilevel Inverter Using Novel Switched Capacitor Converters," IEEE Transactions on Industrial Electronics, vol. 66, no. 11, pp. 8521-8532, 2019.

[17] W. Peng, Q. Ni, X. Qiu, and Y. Ye, "Seven-Level Inverter with Self-Balanced Switched-Capacitor and Its Cascaded Extension," IEEE Transactions on Power Electronics, 2019.

[18] Y. Hinago and H. Koizumi, "A switched-capacitor inverter using series/parallel conversion with inductive load," IEEE Transactions on industrial electronics, vol. 59, no. 2, pp. 878-887, 2011.

[19] R. Barzegarkhoo, M. Moradzadeh, E. Zamiri, H. M. Kojabadi, and F. Blaabjerg, "A new boost switched-capacitor multilevel converter with reduced circuit devices," IEEE Transactions on Power Electronics, vol. 33, no. 8, pp. 6738-6754, 2017.

[20] T. Roy and P. K. Sadhu, "A Step-up Multilevel Inverter Topology using Novel Switched Capacitor Converters with Reduced Components," IEEE Transactions on Industrial Electronics, 2020.

[21] Y. Ye, S. Chen, X. Wang, and K. W. E. E. Cheng, "Self-Balanced 13-Level Inverter Based on Switched-Capacitor Structure and Hybrid PWM Algorithm," IEEE Transactions on Industrial Electronics, 2020.

[22] M. F. Talooki, R. Khosravi, and E. Samadaei, "A Novel High Step-Up Switched-Capacitor Multilevel Inverter with Self Voltage Balancing," IEEE Transactions on Power Electronics, 2020.

[23] M. D. Siddique, S. Mekhilef, A. Sarwar, A. Alam, and N. M. Shah, "Dual asymmetrical DC voltage source based switched capacitor boost multilevel inverter topology," IET Power Electronics, vol. 13, no. 7, pp. 1481-1486, 2020.

[24] M. J. Sathik et al., "Switched-capacitor multilevel inverter with self-voltage-balancing for high-frequency power distribution system," IET Power Electronics, 2020.

[25] P. Panda, P. R. Bana, and G. Panda, "A Switched-Capacitor Self-Balanced High-Gain Multilevel Inverter Employing a Single DC Source," IEEE Transactions on Circuits and Systems II: Express Briefs, 2020.

[26] J. Zeng, W. Lin, D. Cen, and L. Junfeng, "Novel K-Type Multilevel Inverter with Reduced Components and SelfBalance," IEEE Journal of Emerging and Selected Topics in Power Electronics, 2019.

[27] Y. Ye, S. Chen, X. Zhang, and Y. Yi, "Half-Bridge Modular Switched-Capacitor Multilevel Inverter with Hybrid Pulse Width Modulation," IEEE Transactions on Power Electronics, 2019.

[28] N. Sandeep, J. S. M. Ali, U. R. Yaragatti, and K. Vijayakumar, "Switched-capacitor-based quadruple-boost ninelevel inverter," IEEE Transactions on Power Electronics, vol. 34, no. 8, pp. 7147-7150, 2019.

[29] N. Sandeep, J. S. M. Ali, U. R. Yaragatti, and K. Vijayakumar, "A self-balancing five-level boosting inverter with reduced components," IEEE Transactions on Power Electronics, vol. 34, no. 7, pp. 6020-6024, 2019.

[30] S. Ramaiah, N. Lakshminarasamma, and M. K. Mishra, "Multisource switched capacitor based boost multilevel inverter for photovoltaic-based systems," IEEE Transactions on Power Electronics, vol. 35, no. 3, pp. 2558-2570, 2019.

[31] S. S. Lee, Y. Bak, S.-M. Kim, A. Joseph, and K.-B. Lee, "New Family of Boost Switched-Capacitor 7-Level Inverters (BSC7LI)," IEEE Transactions on Power Electronics, 2019.

[32] A. Taghvaie, J. Adabi, and M. Rezanejad, "A self-balanced step-up multilevel inverter based on switched-capacitor structure," IEEE Transactions on Power Electronics, vol. 33, no. 1, pp. 199-209, 2018.

[33] S. S. Lee, “A single-phase single-source 7-level inverter with triple voltage boosting gain,” IEEE Access, vol. 6, pp. 30005-30011, 2018

[34] S. S. Lee, "Single-stage switched-capacitor module (S $3 \mathrm{CM}$ ) topology for cascaded multilevel inverter," IEEE Transactions on Power Electronics, vol. 33, no. 10, pp. 8204-8207, 2018.

[35] R. S. Alishah, S. H. Hosseini, E. Babaei, M. Sabahi, and G. B. Gharehpetian, "New high step-up multilevel converter topology with self-voltage balancing ability and its optimization analysis," IEEE Transactions on Industrial Electronics, vol. 64, no. 9, pp. 7060-7070, 2017.

[36] R. Barzegarkhoo, H. M. Kojabadi, E. Zamiry, N. Vosoughi, and L. Chang, "Generalized structure for a single phase switched-capacitor multilevel inverter using a new multiple DC link producer with reduced number of switches," IEEE Transactions on Power Electronics, vol. 31, no. 8, pp. 5604-5617, 2015.

[37] Y. Ye, K. W. E. Cheng, J. Liu, and K. Ding, "A step-up switched-capacitor multilevel inverter with self-voltage balancing," IEEE Transactions on industrial electronics, vol. 61, no. 12, pp. 6672-6680, 2014.

[38] E. Babaei and S. S. Gowgani, "Hybrid multilevel inverter using switched capacitor units," IEEE Transactions on industrial electronics, vol. 61, no. 9, pp. 4614-4621, 2013.

[39] M. Saeedian, M. E. Adabi, S. M. Hosseini, J. Adabi, and E. Pouresmaeil, "A Novel Step-Up Single Source Multilevel Inverter: Topology, Operating Principle, and Modulation," IEEE Transactions on Power Electronics, vol. 34, no. 4, pp. 3269-3282, 2019.

[40] J. Liu, W. Lin, J. Wu, and J. Zeng, "A novel nine-level quadruple boost inverter with inductive-load ability," IEEE Transactions on Power Electronics, vol. 34, no. 5, pp. 4014-4018, 2019.

[41] Y. Nakagawa and H. Koizumi, "A Boost-Type Nine-Level Switched Capacitor Inverter," IEEE Transactions on Power Electronics, vol. 34, no. 7, pp. 6522-6532, 2018. 


\section{BIOGRAPHIES OF AUTHORS}
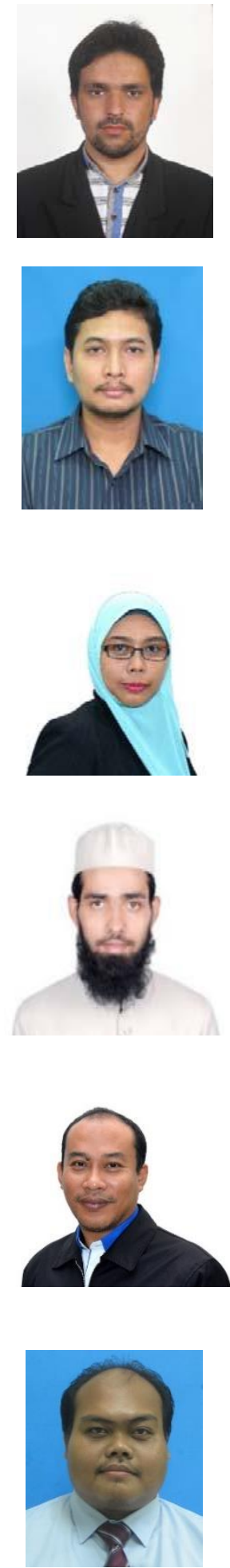

Saifullah Khan received a Bachelor's degree in Electrical Engineering from NED University of Engineering and Technology in Karachi, Pakistan, in 2014 and an MPhil degree in Electrical Engineering from Universiti Teknologi Malaysia, Johor, Malaysia, in 2019. He is currently working towards a Ph.D. degree in power electronics from the School of Electrical Engineering, UTM Malaysia. His research interest includes power converter topologies and modulation strategies for renewable energy integration.

Shahrin bin Md. Ayob was born in Kuala Lumpur, Malaysia. He obtained his first degree in Electrical Engineering, Master in Electrical Engineering (Power), and Doctor of Philosophy (Ph.D.) from Universiti Teknologi Malaysia in 2001, 2003, and 2009, respectively. Currently, he is an associate professor at the School of Electrical Engineering, Faculty of Engineering, Universiti

Teknologi Malaysia. He is a registered Graduate Engineer under the Board of Engineer Malaysia (BEM) and Senior Member of IEEE. His current research interest is the solar photovoltaic system, electric vehicle technology, fuzzy system, and evolutionary algorithms for power electronics applications.

Norjulia Mohamad Nordin received her Bachelor's degree in Electrical Engineering from Universiti Teknologi Malaysia, Johor, Malaysia, in 2006, M. Eng. Sc. Degree in Energy System from The University of New South Wales, Australia, in 2008 and Ph.D. from Universiti Teknologi Malaysia (UTM) in 2016. Currently, she is a senior lecturer at the Universiti Teknologi Malaysia, Johor, Malaysia. Her research interests are AC and DC drive systems, multilevel inverter, and wide bandgap-based power electronic converter.

M Saad Bin Arif received an M. Tech degree in Electrical Engineering with specialization in power

System and Drives and Graduation in Electrical Engineering in 2001 and 2010 respectively. His research area of interest - power electronics, application of power electronics in renewable energy systems, energy systems, and engineering education.

Mohd. Zaki Daud received his Bachelor's degree in electrical engineering from the University Of Southampton and Master of Science in Electrical Power Engineering in 1995 and 1996, respectively. He is currently a lecturer at the School of Electrical Engineering, Faculty of Engineering, Universiti Teknologi Malaysia, Skudai, Johor. His current research is on power electronics converter.

Razman Ayop received the Bachelor's degree in electrical engineering with first-class honors, the master's degree in electrical engineering with specialization in power system, and the Ph.D. degree in electrical engineering from Universiti Teknologi Malaysia (UTM), Johor, Malaysia, in 2013, 2015, and 2018, respectively. He is a Senior Lecturer with UTM and a member of Power Electronics and Drives Research Group, School of Electrical Engineering, Faculty of Engineering, UTM. His research interests include renewable energy and power electronics. 